\title{
Hounsfield units in pseudo subarachnoid hemorrhage: worth looking for
}

\author{
Subramanian Senthilkumaran ${ }^{1}$, Nanjundan Karthikeyan ${ }^{2}$, \\ Namasivayam Balamurugan ${ }^{3}$, Ponniah Thirumalaikolundusubramanian ${ }^{4}$ \\ 'Department of Emergency \& Critical Care, Erode Emergency Care Hospital, Erode, Tamil Nadu, India \\ ${ }^{2}$ Department of Emergency Medicine, Hamad Medical Corporation, Doha, Qatar \\ ${ }^{3}$ Department of Neurosciences, SIMS Chellam Hospital, Salem, Tamil Nadu, India \\ ${ }^{4}$ Department of Internal Medicine, Chennai Medical College Hospital \& Research Center, Irungalur, Trichy, \\ India
}

We read the case report by Kim et al. ${ }^{1}$ with great interest. The authors have noticed non-aneurysmal and non-traumatic subarachnoid hemorrhage $(\mathrm{SAH})$ with the help of cranial computed tomography (CT) scanning in a case of an incomplete hanging and investigated the case thoroughly. From the point of patient safety and quality of care, we would like to highlight the usefulness of Hounsfield units $(\mathrm{HU})$ to distinguish SAH from other mimickers of SAH based on our experience ${ }^{2}$ and the literature.

The subsequent angiography did not detect any aneurysms or vascular malformations or bleeding. Still, the authors had considered SAH secondary to near hanging and provided various probable mechanisms for its occurrence. There are several mimickers of SAH reported in the literature, and one such entity is pseudo-SAH. ${ }^{3}$ Survivors of hanging may develop marked cerebral edema in the acute or subacute phase as observed in this patient. The literature suggests that brain CT in such patients may show high-attenuation areas along the cisterns or cortical sulci, mimicking SAH.

Even though the literature proposes autopsy and CSF studies as the ways to rule out pseudo$\mathrm{SAH}$, meticulous measurement of the density of different visible elements in the CT scan by HU helps to discriminate hyperintensities of SAH from pseudo-SAH. Moreover, this can be done with the available CT scans without additional cost. ${ }^{4}$ Hence the importance of application and utilization of HUs must be imparted to students of health sciences and emergency physicians.

It is also suggested that the utilization of HUs in the interpretation of CT images should be incorporated as a routine in medical audits and quality improvement programs of emergency care and radiology documents so as to ensure patient safety and cost reduction.

\section{CONFLICT OF INTEREST}

No potential conflict of interest relevant to this article was reported.
elSSN: 2383-4625

Received: 16 June 2017

Revised: 26 June 2017

Accepted: 26 June 2017

Correspondence to:

Subramanian Senthilkumaran Department of Emergency \& Critical Care Medicine, Be Well Hospitals, 5 Gandhiji Road, Erode, Tamil Nadu, India E-mail: maniansenthil@yahoo.co.in

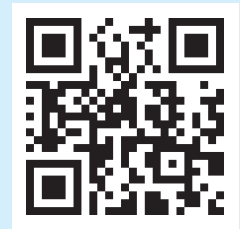

How to cite this article: Senthilkumaran S, Karthikeyan N, Balamurugan $\mathrm{N}$

Thirumalaikolundusubramanian $\mathrm{P}$. Hounsfield units in pseudo subarachnoid hemorrhage: worth looking for. Clin Exp Emerg Med 2017;4(3):186-187.

This is an Open Access article distributed under the terms of the Creative Commons Attribution Non-Commercial License (http:// creativecommons.org/licenses/by-nc/4.0/). 


\section{REFERENCES}

1. Kim TH, Lee SH, Kim DH, et al. Non-aneurysmal and nontraumatic subarachnoid hemorrhage after attempted suicide by incomplete hanging. Clin Exp Emerg Med 2017;4:56-9.

2. Senthilkumaran $S$, Balamurugan N, Menezes RG, Thirumalaikolundusubramanian P. Role of Hounsfield units to distinguish pseudo-subarachnoid hemorrhage. Clin Toxicol (Phila)
2011:49:948.

3. Senthilkumaran S, Balamurgan N, Menezes RG, Thirumalaikolundusubramanian $\mathrm{P}$. Bee sting and subarachnoid hemorrhage: an insight. Am J Emerg Med 2012;30:1310-1.

4. Senthilkumaran S, Sweni S, Balamurugan N, Jena NN, Thirumalaikolundusubramanian P. Hounsfield units in pseudosubarachnoid hemorrhage-an old yet fascinating tool. Am J Emerg Med 2015;33:1095. 